\title{
Representações Sociais de Professores do Ensino Fundamental sobre Violência Intrafamiliar
}

\author{
Sandra Francesca Conte de Almeida ${ }^{1}$ \\ Universidade Católica de Brasília \\ Maria Cristina Amélia Borges dos Santos \\ Centro de Ensino Superior do Brasil - Brasília \\ Tânia Maria de Freitas Rossi \\ Universidade Católica de Brasília
}

\begin{abstract}
RESUMO - Este estudo focaliza as representações sociais de professores do ensino fundamental acerca da violência intrafamiliar. A amostra foi de 94 professores de escolas públicas e privadas (Distrito Federal e Goiás), graduandos em Pedagogia. Na coleta de dados, aplicou-se um questionário visando apreender as representações sobre violência intrafamiliar, nas dimensões informação, campo das representações sociais e atitudes dos sujeitos diante de casos comprovados ou suspeitos de alunos vitimados pela violência intrafamiliar. Os resultados apontam contradições e ambivalências entre os sentimentos e as atitudes dos professores em relação ao fenômeno. Indicam, ainda, que a representação social da violência intrafamiliar, para grande parte dos sujeitos, ainda passa pela consideração do poder da autoridade paterna/familiar, que dá direito aos pais de educar seus filhos como melhor lhes convier, indicando a necessidade da capacitação de professores, no âmbito da formação inicial e continuada, para lidar adequadamente com a problemática da violência intrafamiliar, no cotidiano escolar.
\end{abstract}

Palavras-chave: representações sociais; violência intrafamiliar; professores; relação entre família e escola.

\section{Elementary and Middle School Teachers' Social Representation Concerning Inner-Family Violence}

\begin{abstract}
This study is focused on the social representations of elementary and middle school teachers about the inner-family violence. The used sample encompasses 94 teachers of public and private schools (Federal District and Goiás, Brazil), undergraduate students in Pedagogy. In the data collection process a questionnaire was applied in order to apprehend the representations about the inner-family violence in the dimensions of information, social representation field and attitudes, regarding proven and suspicious cases of students, victims of inner-family violence. The results point to contradictions and ambivalences between the teacher's feeling and attitudes in relation to the phenomenon. They also indicate that the social representation of inner-family violence for a great part of the individuals, still passes through the consideration of the authority power of parents and families, which gives them the right to educate their children as they deem most appropriate, indicating the necessity of training for teachers, in the initial and continuous education, to adequately deal with the inner-family violence problem in the school daily issues.
\end{abstract}

Key words: social representations; inner-family violence; teachers; family school relationship.

Investigar a violência intrafamiliar, por si só, remete o pesquisador a uma multiplicidade causal: a violência originada na relação conjugal, no desemprego, em distúrbios de algum membro da família, na miséria, na má distribuição de renda (Guerra \& Azevedo, 2000). Acrescentar a esse discurso a rede relacional, que é a escola, insere o problema em uma conjuntura pública e social mais ampla, que ultrapassa o espaço familiar, na qual o Estado, para garantir os direitos que instituiu, necessita da solidariedade e colaboração da sociedade. Esta, em seu papel de mediadora de soluções, pode denunciar e notificar situações de violência intrafamiliar contra crianças e adolescentes aos órgãos públicos de direito. A escola é parte da sociedade, instituição

1 Endereço: Universidade Católica de Brasília, Pró-Reitoria de Pós-Graduação e Pesquisa, Campus Universitário II, SGAN 916, módulo B, W5 Norte, Brasília, DF, Brasil, 70790-160. E-mail: sandraf@pos.ucb.br social educativa reconhecida como espaço público e de cidadania, locus privilegiado de referência de valores sociais, culturais e éticos digno de credibilidade pela própria função (in)formativa que desempenha.

No entanto, um dos maiores empecilhos ao desempenho esperado da sociedade e de suas instituições sociais, dentre as quais a escola, é a omissão decorrente de crenças, de pontos de vista e de conceitos equivocados, baseados em concepções conservadoras e representações distorcidas da realidade e das condições de vida das pessoas. Dela derivam ações e atitudes nem sempre condizentes com o objetivo de promoção e atenção à saúde, desenvolvimento e bem-estar dos sujeitos nos diversos ambientes em que estão inseridos.

Por se constituírem em uma forma de conhecimento socialmente elaborado e partilhado, tendo uma finalidade prática e concorrendo para a constituição de uma realidade comum de 
um dado grupo social, elegeu-se no contexto deste trabalho, como objeto de investigação, as representações sociais de professores do ensino fundamental acerca da violência intrafamiliar contra crianças e adolescentes.

\section{Das Representações Sociais e sua Teoria: Uma Breve Apresentação}

Para Moscovici (1978), a representação social é "uma modalidade de conhecimento particular que tem por função a elaboração de comportamentos e a comunicação entre indivíduos" (p. 26). Analisando esse conceito, Bonfim e Almeida (1992) explicam que é modalidade particular porque só é representação social o conhecimento advindo do senso comum, ou seja, elaborado socialmente na vida cotidiana e que tem como função interpretar e agir sobre a realidade. Quanto ao seu papel na formação de condutas, a representação social não só modela o comportamento como também justifica a sua expressão. Em última instância, a representação social prepara a ação, conduz o comportamento, modifica e reconstitui os elementos do ambiente no qual vai ocorrer o comportamento. Finalmente, quanto à comunicação, o papel da representação social é o de constituir um instrumento por meio do qual os grupos apreendem formas de se envolver e de se relacionar, com a mediação da linguagem.

Ainda, para Moscovici (2003), a finalidade das representações é transformar o não-familiar em familiar. E a relação estabelecida pelo autor entre familiar e não-familiar diz respeito ao universo consensual no qual os grupos sociais se inscrevem. A dinâmica das representações é, portanto, uma dinâmica de familiarização, na qual os objetos, pessoas e acontecimentos são percebidos e compreendidos em relação a prévios encontros e paradigmas. Como resultado disso, "a memória prevalece sobre a dedução, o passado sobre o presente, a resposta sobre o estímulo e as imagens sobre a "realidade" (Moscovici, 2003, p. 55).

As representações sociais se sobressaem em relação a outros fenômenos no plano simbólico porque surgem da realidade cotidiana, a qual tem prevalência sobre outras realidades como a religiosa e a científica, por exemplo. E essa prevalência é determinada tanto pela linguagem - que não só fundamenta o cotidiano como fornece as respostas necessárias ao sentido desse cotidiano - como pela estrutura social da realidade, em cuja interação o indivíduo compartilha sua subjetividade, estabelecendo diferenças entre realidades vividas e outras que existem na consciência. Essas outras realidades têm, assim, um caráter finito de significação (Bonfim \& Almeida, 1992).

Em resumo, a teoria das representações sociais parte da diversidade dos indivíduos, das atitudes e dos fenômenos, considerando sua estranheza e imprevisibilidade, para tentar descobrir de que forma indivíduos e grupos podem construir um mundo estável e previsível nesse contexto (Moscovici, 2003).

\section{Do Conteúdo das Representações Sociais e Suas Dimensões}

Para Moscovici (2003), as representações sociais encontram-se em um referencial de pensamento preexistente, dependendo, portanto, de um sistema de crenças, valores e imagens. Do ponto de vista cognitivo, fenômenos novos podem ser incorporados a "modelos explicativos e justificativos que são familiares e conseqüentemente aceitáveis. Esse processo de troca e composição de idéias (que ocorre por meio do discurso) é sobretudo necessário, pois ele responde às duplas exigências dos indivíduos e das coletividades" (p. 216). Por um lado, constroem-se sistemas de pensamento e de compreensão e, por outro, adotam-se visões consensuais de ação, mantendo o vínculo social e a continuidade da idéia.

Essas informações são filtradas e arquivadas na memória, formando esquemas coerentes e constituindo uma matriz cognitiva do objeto, de modo a permitir ao sujeito compreendê-lo e agir sobre ele (Santos, 1994). Essa troca possibilita o acesso aos fenômenos sociais, acesso esse no qual as práticas do conhecimento e do conhecimento prático têm um papel fundamental. Trata-se, para Jodelet (1993), de um crivo de leitura da realidade.

O conteúdo e o sentido das representações sociais podem ser estruturados em três dimensões:

1. a informação, definida por Bonfim e Almeida (1992) como "o montante de conhecimentos, tanto qualitativos como quantitativos, que existem acerca de um objeto social aprendido por um grupo específico" (p.84). Para Santos (1994), pela informação pode-se distinguir níveis referentes ao conhecimento do objeto;

2. o campo da representação, que constitui a tendência de respostas "em um grupo que engloba uma hierarquia de elementos, os quais reforçam um grupo a outro, ou a partir das influências que recebe no seu contexto" (Bonfim \& Almeida, 1992, p. 84). Santos (1994) explica que se trata de uma unidade estruturada hierarquicamente, demonstrando a forma como o conteúdo se organizou;

3. a atitude, que expressa as orientações sobre o objeto, sejam elas positivas ou negativas. Segundo Santos (1994), a atitude e a informação são dois elementos do conteúdo que se estruturam no campo das representações sociais.

A pesquisa objeto deste trabalho insere-se na dimensão fenomenológica de análise e discussão das representações sociais, qual seja, a que toma as representações sociais como objeto da realidade social e visa a identificar os elementos que as constituem, em termos de seu conteúdo propriamente dito (Oliveira \& Werba, 2003).

\section{Família/Escola e Violência Intrafamiliar}

A organização do homem em grupos é algo inerente à condição humana. $\mathrm{O}$ filhote de homem necessita de cuidados essenciais para garantir sua sobrevivência, a saber: alimentação, proteção e ensinamentos. A garantia de sua sobrevivência desde as mais primitivas culturas até a moderna civilização, em todas as sociedades, é fruto de seu pertencimento a agregações sociais. A família constitui uma dessas agregações sociais, assim como a sociedade, em constante mudança. Entretanto, a família, tal como a reconhecemos hoje, é fruto de mudanças na história do homem em sociedade, como observa Ariès (1981). Esse autor relata, a partir de uma análise iconográfica, que o sentimento de família era desconhecido na Idade Média, nascendo somente nos séculos XV e XVI e vindo a exprimir todo o seu vigor no século XVII. Para Ariès, a família conjugal seria consequiência de uma evolução nas instituições sociais ou, ainda, de uma mudança, uma cisão entre o público e o privado.

De acordo com o art. 227 da Constituição Federal bra- 
sileira, de 1988,

(...) os pais são os responsáveis pela formação e proteção dos filhos, não só pela detenção do pátrio poder, mas pelo dever de garantir-lhes os direitos fundamentais assegurados pela constituição, tais como a vida, a saúde, a alimentação e a educação (Brasil, 1988).

A lei garante, portanto, a responsabilidade da família e a sua punição, em caso de abuso e violência contra crianças e adolescentes.

Koller e De Antoni (2004) apresentam os fatores de risco relevantes para a avaliação de casos de violência intrafamiliar, segundo os diferentes contextos ecológicos (Bronfenbrenner, 1996) nos quais a pessoa está inserida. Destacam, entre tantos, alguns fatores de risco: a história anterior tanto da vítima quanto do abusador, bem como a ausência de recursos terapêuticos e de conhecimento do Estatuto da Criança e do Adolescente; o sentimento de solidão e de insegurança no ambiente familiar somado aos segredos de família, problemas como estresse por saúde e questões financeiras, o desemprego e o empobrecimento; baixa auto-estima, comunicação ineficiente na família somada a práticas disciplinares punitivas com a naturalização e a banalização da violência e a aceitação da punição corporal pela sociedade; e, ainda, fatores relativos à cognição e à educação, tais como: quociente intelectual baixo associado a baixo nível de escolaridade e capacidade verbal limitada, família com baixo nível de escolaridade e professores sem capacitação e desconhecedores das políticas públicas.

Em termos gerais, as formas agressivas de adultos contra crianças no seio da família são observadas em um quadro de abusos que proporciona as condições para a repetição de condutas. Nesse quadro, os abusos podem ser classificados em violência doméstica e violência intrafamiliar. Ravazzola (1997) não faz diferença entre as duas expressões; ambas significam a violência sofrida por um membro da família que recebe reiterados maus tratos por parte de outro.

$\mathrm{Na}$ literatura norte-americana existe uma posição assumida de que o termo violência doméstica deve ser usado para referir-se aos atos cometidos pelos homens contra as mulheres. Também se inclui nesse rol, a violência cometida entre casais de adultos ou de adolescentes, como ainda aquela que acontece entre pessoas que co-habitam o mesmo espaço físico e de casais de namorados heterossexuais ou homossexuais (Koller \& De Antoni, 2004).

O termo violência doméstica, no Brasil, é utilizado comumente para referir-se à agressão física ocorrida em qualquer relação de parentesco. Como uma alteração conceitual, propõe-se a utilização do termo violência intrafamiliar para descortinar o rompimento do paradigma de que a violência possui um caráter privado e íntimo. Assim sendo, a expressão violência intrafamiliar compreende "todas as formas de violência (abuso sexual, físico e emocional, abandono e negligência) e todas as configurações familiares possíveis (entre pais e filhos, casal, irmãos e filhos para com pais)" (Koller \& De Antoni, 2004, p. 297). Vista nesta perspectiva, a violência no contexto familiar passa a ser encarada como um fenômeno de domínio público e não privado.

Guerra (2001) esclarece que os pais podem exercer vários tipos de violência contra os filhos com fins pretensa- mente disciplinares ou com outros objetivos, sendo a violência caracterizada como: violência física, violência sexual, violência psicológica e por negligência.

A violência física é de difícil conceituação, na atualidade, tendo em vista as mudanças de enfoque que ocorreram nos últimos 30 anos e que levaram a definições que envolvem desde os maus tratos com danos físicos (como fraturas, queimaduras, lesões diversas, entre outras) até o ato não intencional. Ainda assim, a autora reitera que esse tipo de violência corresponde ao uso da força física no relacionamento com a criança ou com o adolescente por parte de seus pais, em uma relação pautada no poder disciplinador do adulto e na desigualdade adulto-criança.

A violência sexual é configurada como todo ato ou jogo sexual, relação hetero ou homossexual entre adulto e criança, tendo por finalidade estimular sexualmente a criança para que o adulto obtenha algum grau de satisfação sexual.

A violência por negligência é representada por uma omissão do adulto, no sentido de falhas que não resultem da condição de vida. Também para Carvalho e Rodrigues (1998), a negligência é considerada como a omissão da família em prover a criança ou adolescente em suas necessidades físicas e emocionais podendo ser consideradas faltas graves se incompatíveis com os recursos socioeconômicos da família.

A violência psicológica é também chamada de tortura psicológica e pode ser observada mediante depreciações à criança, atos que causem sofrimento mental, bloqueio à auto-aceitação, ameaças e outros. Esse tipo de violência é evidenciado quando da interferência negativa de um adulto sobre a criança e sua competência social. Costuma estar associada a outros tipos de violência. O Ministério da Saúde (citado por Guerra, 2001) destaca outras formas: o ato de rejeitar, quando o adulto não aceita a criança, não reconhece seu valor nem tampouco a legitimidade de suas necessidades; o ato de isolar, quando o adulto afasta a criança ou o adolescente de experiências sociais próprias a sua idade; o ato de aterrorizar, quando o agressor instaura clima de medo, com agressões verbais, atemorizando-a a ponto de fazê-la crer que o mundo é hostil; o ato de ignorar, quando o adulto não estimula o crescimento emocional e intelectual da criança ou do adolescente.

Quando a família não garante a proteção necessária a seus membros, por motivos os mais diversos, o Estado cria instituições com o intuito de re-orientar o curso de sua sociedade. Surge, então, o Conselho Tutelar, criado pelo Conselho Nacional dos Direitos da Criança e do Adolescente (CONANDA), a fim de regulamentar o artigo 227 da Constituição Federal, como órgão permanente e autônomo, não jurisdicional, encarregado pela sociedade de zelar pelo cumprimento dos direitos da criança e do adolescente. O Conselho Tutelar tem como atribuiçõos previstas em lei - Estatuto da Criança e do Adolescente - ECA, atender às crianças e aos adolescentes; atender e aconselhar aos pais ou responsáveis; determinar, dentre outras, as seguintes medidas: de orientação, de apoio e acompanhamento; de inclusão em programa comunitário, à família, à criança e ao adolescente (Brasil, 1990).

Observa-se, de acordo com Koller e Amazarray (1998), que os maus tratos contra crianças e adolescentes têm recebido maior atenção nos dias de hoje, em contraposição ao que antes - década de 50 do século passado - era tido 
como tabu. Assim, as autoras sugerem que a freqüência de abusos permanece regularmente constante e o que pode ter mudado é a atenção dada atualmente ao problema. Analisam, ainda, que uma tomada maior de consciência por parte dos profissionais acerca de abuso sexual contra crianças pode ter sua origem em dois aspectos: o primeiro deles evidencia um crescente movimento em prol dos direitos da criança e o segundo aponta maior conhecimento e preocupação com a saúde tanto mental como física das mesmas. Contudo, apesar de esse quadro vislumbrar uma melhoria, ele não revela o despreparo que envolve os profissionais das esferas da saúde, da educação e da justiça na condução e tratamento adequado no enfrentamento de casos. E concluem as autoras que, apesar da crescente atenção por parte dos pesquisadores em relação ao tema do abuso sexual de crianças, o trabalho nesse campo é fragmentado, desorganizado e em geral metodologicamente difuso.

A violência intrafamiliar, apesar de ocorrer na esfera das relações privadas, termina por inserir-se no contexto de outras relações vinculares da criança, sendo a escola um desses contextos, e aí exercendo seus efeitos na relação ensinoaprendizagem.

A escola, como espaço público, mas em interdependência como família, aparece, portanto, como um dos mais importantes agentes socializadores da criança, por tratar-se de um espaço da cidadania, conforme definido por Souza Santos (citado por Rosa, 2004, p. 31): "o espaço da cidadania é constituído pelas relações sociais da esfera pública entre cidadãos e o Estado".

De acordo com Brino e Williams (2003), a escola mostra-se o lugar ideal para detecção e intervenção em casos de abuso sexual infantil, pois na maioria das vezes o principal agressor encontra-se na família e deve a escola ter como objetivos a garantia da qualidade de vida de sua clientela, bem como promover sua cidadania. Essas autoras, ao realizarem uma pesquisa com professores de escolas municipais da cidade de São Paulo, com o intuito de conhecer o universo de informações que os mesmos tinham sobre abuso sexual infantil, indicaram, em seus resultados, que a maioria das educadoras possuía informações insuficientes acerca do tema e adotava por sua vez procedimentos inadequados diante dos casos de crianças que sofreram abusos sexuais.

Em relação à adoção de procedimentos, pela escola, em termos legais há uma passagem do problema da violência intrafamiliar da esfera privada para a pública, passagem esta facilitada pela estreita relação entre essas instituições. Nesse sentido, Guerra (2001) descreve

(...) todo ato ou omissão praticado por pais, parentes ou responsáveis contra crianças elou adolescentes que sendo capaz. de causar dano físico, sexual elou psicológico à vitima implica, de um lado, numa transgressão do poder/dever de proteção do adulto e, de outro, numa coisificação da infância, isto é, numa negação do direito que crianças e adolescentes têm de serem tratados como sujeitos e pessoas em condição peculiar de desenvolvimento (p. 32).

\section{Método}

Trata-se de uma pesquisa exploratória e descritiva, de natureza qualitativa associada a uma abordagem quantitativa, com o objetivo de levantar as representações sociais de professores do ensino fundamental acerca da violência intrafamiliar.

\section{Procedimentos}

$O$ instrumento de pesquisa - Adotou-se o questionário com perguntas fechadas e abertas como instrumento de coleta de dados. O questionário consistiu, basicamente, em duas partes: a primeira contendo perguntas fechadas, denominada características gerais da amostra. Nesta primeira parte foram levantadas as variáveis independentes da amostra, tais como: idade, sexo, tipo de escola, tempo de serviço como docente, local de moradia, entre outros. A segunda parte do questionário continha perguntas abertas, por meio das quais buscou-se levantar os construtos representacionais dos professores (variável dependente) sobre a violência intrafamiliar, nas seguintes dimensões estruturais, conforme a teoria das representações sociais:

a) Perguntas relacionadas às informações que os sujeitos possuíam sobre violência intrafamiliar e as fontes de informação: mídia, relatos de pesquisas, conversas informais dentre outras.

b) Perguntas relacionadas ao campo das representações dos sujeitos acerca da violência intrafamiliar, expressas por meio de: frases, sentimentos ou palavras que definem violência intrafamiliar e pela indicação de sinais e/ou sintomas observados nos alunos.

c) Perguntas nas quais buscou-se averiguar quais as atitudes dos professores diante de casos, comprovados ou suspeitos, de alunos em situação de violência intrafamiliar.

\section{Os participantes e a coleta dos dados}

Optou-se por aplicar os questionários em estudantes de duas instituições de Ensino Superior, uma do entorno de Brasília, Estado de Goiás, e outra de uma cidade satélite do Distrito Federal.

Todos os participantes da pesquisa eram professores em exercício no ensino fundamental, de $1^{\mathrm{a}}$ à $4^{\mathrm{a}}$ séries (leigos ou com magistério de nível médio), graduandos em Pedagogia. Essa opção decorreu das seguintes questões e inquietação: os professores em processo de formação superior estariam mais atentos às variáveis que incidem sobre a relação professor/aluno, especialmente no caso de aluno sofrendo de violência intrafamiliar? Estariam os sujeitos preparados, do ponto de vista pedagógico e desde a perspectiva da cidadania, para identificar, acolher e encaminhar alunos vitimizados pela violência intrafamiliar?

A coleta de dados foi realizada aleatoriamente em setembro de 2004. Foram aplicados 70 questionários em cada instituição, sendo que na instituição do estado de Goiás 55 sujeitos se dispuseram a responder e na instituição do Distrito Federal somente 39 o fizeram. A faixa etária dos sujeitos foi de 19 a 49 anos.

\section{Tratamento dos Dados}

A primeira parte do questionário, composta de perguntas fechadas, recebeu um tratamento quantitativo (freqüencial) e 
resultou nos dados de caracterização geral dos participantes.

Para a segunda parte do questionário, que correspondia ao levantamento das representações sociais em suas dimensões estruturais, os dados foram tratados qualitativa e quantitativamente. Foram criadas categorias para cada dimensão pesquisada, a partir de critérios descritos por Bardin (1977) para a análise de conteúdo, que incluíam, além de codificações sintáticas, léxicas ou semânticas, a freqüência desses códigos.

\section{Resultados e Discussão}

\section{Dados Demográficos (características gerais da amostra)}

A amostra compreendeu 94 professores do ensino fundamental da rede pública e privada de ensino ( $1^{\mathrm{a}}$ à $4^{\mathrm{a}}$ séries). A idade dos sujeitos foi categorizada em seis grupos e observou-se que $37 \%$ dos participantes pesquisados tinham idade entre 26 e 32 anos e que $27 \%$ tinham idade abaixo de 26 anos, com desvio padrão de 7,14 anos. Trata-se de uma amostra composta, predominantemente, por adultos-jovens (média de idade: 30,4 anos).

Quanto à localização da moradia, 58,5\% moravam no estado de Goiás (entorno) e 41,5\% no Distrito Federal. Quanto ao gênero, 92,6\% eram do sexo feminino e 7,4\% do sexo masculino. Quanto ao tipo de escola em que trabalhavam, a grande maioria, 62,8\%, lecionava em escola privada e $36,2 \%$ em escola pública e 1,1\% não informaram. Lecionavam na $1^{a}$ série do ensino fundamental $29 \%$ dos participantes, $21 \%$ na $2^{\mathrm{a}}$ série, $16 \%$ na $3^{\mathrm{a}}$ e na $4^{\mathrm{a}}$ séries. Entre os participantes entrevistados, $57,4 \%$ fizeram curso de magistério de ensino médio e 42,6\% não o fizeram. Quanto ao tempo de trabalho como professor, observou-se que $52 \%$ tinham menos de cinco anos de atividade profissional, 32\% tinham entre seis e 10 anos e $9 \%$ entre 11 e 15 anos.

\section{Dimensões Estruturais das Representações Sociais}

\section{Unidade de registro 1 (Informações)}

Mesmo sendo expressivo o percentual de participantes que se informam pela mídia $(56,4 \%)$, os efeitos desse modo de divulgação da violência intrafamiliar podem ainda não ser suficientemente motivadores para ações mais amplas no combate ao problema, haja vista a veiculação de informações entre grupos (por meio de conversa informal) parecer mais forte $(76,6 \%)$, não somente em razão do número em si, mas das próprias malhas de construção e comunicação das representações sociais.

Informações sobre violência intrafamiliar obtidas a partir de conversas informais denotam conhecimentos surgidos da vida cotidiana, servindo apenas como meio de estabelecimento de relações entre pessoas (Freitas \& Castro, 2004). Paralelamente, essa mesma característica de informalidade na obtenção de informações é que pode induzir à familiaridade com o problema que, por sua vez, se torna comum aos olhos de todos.

O conhecimento da violência intrafamiliar por meio de grupos sociais corresponde a uma das três funções básicas de representação da realidade a que se refere Jodelet (1993): a função cognitiva de integração do assunto (no caso, a vio- lência intrafamiliar) que, com as demais - interpretação da realidade e orientação de condutas -, constitui o processo que vai garantir a objetivação das representações sociais. Por outro lado, em termos de violência intrafamiliar, a circulação do tema em grupos sociais informais mantém o fenômeno dentro do modelo concebido como pertencente à esfera privada/familiar e, ao mesmo tempo, naturaliza o fenômeno.

“(...) não concordo com a questão da criança ser intocável" (P-21)2; “(...) bater faz parte (sem agressão)” (P-25); "devemos educar nossos filhos à nossa maneira (...)" (P25); “(...) até que ponto devemos defender a criança que só faz coisas erradas?" (P-7).

Assim, as conversas informais, ao se constituírem na mais destacada fonte de informação dos participantes da pesquisa, não concorrem para o delineamento do problema em uma perspectiva teórico-conceitual avalizada do ponto de vista científico e política e socialmente mais justa e lúcida. Apenas $12,77 \%$ dos professores pesquisados obtêm informações acerca da violência intrafamiliar por meio de palestras, seminários, pesquisas e outros meios cientificamente mais aceitos. Parece que o fato de estarem cursando o nível superior de ensino não exerce influência sobre o modo de apropriação do conhecimento a respeito da violência intrafamiliar.

Com relação à questão sobre o conhecimento do Estatuto da Criança e do Adolescente e a opinião sobre o mesmo, $85,1 \%$ dos participantes responderam conhecê-lo (SIM) e 9,6\% responderam NÃO.

É interessante observar que na resposta anterior, 76,6\% dos professores pesquisados obtêm informações sobre a violência intrafamiliar nos seus grupos sociais, de maneira informal, e, nesta resposta, 85,1\% declararam conhecer o ECA. Confirma-se a noção de que as informações grupais são mais relevantes, ou seja, conhecer o ECA pouco (ou nada) representa, já que o Estatuto sequer foi citado como fonte de conhecimento, o que parece indicar que em nada influencia o modelo estabelecido da representação social da violência intrafamiliar.

Dos participantes que afirmaram conhecer o ECA, $41,5 \%$ não concordam com suas normas: "este estatuto libera por demais a impunidade a jovens conscientes do que fazem e pouco respeitam ao próximo"(sic) (P-38); "esta lei 'protege' demais a ponto de prejudicar, principalmente ao adolescente. É como se esta lei tornasse eles incapazes, dando-lhes o direito de serem inconseqüentes"(sic) (P-36).

Um contingente de $31,9 \%$ concorda parcialmente com o ECA: "para certas situações o ECA é correto, para outras ele é muito vago, não atende às necessidades da sociedade"( sic) (P- 49).

Somente 10,6\% concordam plenamente com o Estatuto: "essa lei é muito boa no sentido de coibir certos comportamentos tanto de pais e/ou adultos envolvidos com a criança" (sic) (P-20).

No sentido geral, se $73,4 \%$ dos professores pesquisados não concordam ou discordam parcialmente das regras do ECA, pode-se inferir daí três leituras: o Estatuto é pouco divulgado nas escolas, ratificando-se a presença do peso

2 P-21: a letra P corresponde a Professor pesquisado e o número 21 ao código de identificação atribuído ao sujeito. Usar-se-á a mesma terminologia na explicitação de fragmentos da fala de outros participantes. 
das informações e da rede de comunicações grupais; a falta de discussão mais aprofundada sobre a lei resulta em um conhecimento superficial e às vezes equivocado de seus objetivos e conteúdo ou, ainda, a amostra pode apresentar-se conservadora diante do problema, mantendo a tradição de que questões privadas só interessam "a quem de direito". Em quaisquer dessas leituras confirma-se a idéia de manutenção do modelo de autoridade ao qual se referiu anteriormente.

Em relação à questão sobre as instituições e/ou órgãos conhecidos pelos participantes destinados à proteção, atendimento e encaminhamento de crianças/alunos em situação de violência intrafamiliar, as respostas foram: $52,13 \%$ citaram o Conselho Tutelar- CT; 29,79\% citaram instituições policiais e judiciárias (CAJE - Centro de Atendimento Juvenil Especializado, Juizado de menores e outros); 14,89\% informaram a própria escola, por meio do assistente social, do psicopedagogo e do orientador educacional e 3\% conheciam outras instituições sociais. Do total, 25,53\% não souberem responder à questão. Como as repostas não eram excludentes, alguns participantes indicaram mais de um item.

Em resumo, se o conhecimento dos órgãos/instituições equipara-se à representação negativa que os professores pesquisados têm do ECA, pode-se inferir que na perspectiva da teoria das representações sociais a análise das respostas, relativas às questões da unidade de registro "informação", demonstra uma atividade cognitiva sobre o fenômeno explicada por duas das três hipóteses aventadas por Moscovici (2003), ao justificar as propriedades das representações sociais:

1. A desiderabilidade, segundo a qual pessoas ou grupos criam imagens e constroem crenças que se configuram em imagens e sentenças, resultado de distorções subjetivas da realidade: "(...) bater faz parte (mas sem agressão)" (P- 25); “(...) uma lei (ECA) que ampara as crianças e adolescentes quando a sociedade quer punir" (P-32).

2. $\mathrm{O}$ controle, que diz respeito às representações criadas pelo grupo (conversas informais) para filtrar as informações vindas do ambiente (via mídia). Com isso direciona-se o pensar dos indivíduos e as informações filtradas constituem manipulação do pensamento e da realidade: "o jovem não pode responder por seus atos mas podem decidir os governantes" (P-38) (sic).
Deduz-se, da análise feita, que os participantes da pesquisa, ao manterem seu conhecimento sobre violência intrafamiliar no nível da informalidade, desconsideram aspectos importantes que envolvem o problema - desde a sua compreensão e entendimento com base em estudos e pesquisas até a responsabilidade social diante dele. Aparentam, dessa forma, pouca qualificação para a realização de intervenções adequadas caso venham a se deparar com este tipo de problemática no cotidiano escolar. Considerando o papel do professor como agente de educação e de formação da cidadania, ficam claras as falhas de sua atuação nesse processo, corroborando resultados de pesquisa semelhantes obtidos por Brino (2002), Brino e Williams (2003) e Koller e Lisboa (2004).

\section{Unidade de registro 2 (campo das representações)}

No segundo grupamento de respostas, correspondente à unidade de registro "campo das representações sociais", os resultados obtidos referiram-se à pergunta - "quando você escuta a expressão violência intrafamiliar, ou pensa a respeito dessa questão, quais são as palavras, frases ou sentimentos que lhe vêm à mente para definir essa situação?"

Para 59,6\% dos participantes, a representação da violência intrafamiliar se configura por meio da definição de suas possíveis causas; para 36,2\%, a definição passa pelos sentimentos gerados pelo fenômeno; para 22,3\%, as consequiências da violência intrafamiliar é que definem o objeto representado; e somente $18,1 \%$ definiram violência intrafamiliar conforme os critérios apontados na literatura especializada.

Destaca-se, de início, que o enunciado da pergunta passa pelo imaginário dos sujeitos, na medida em que se busca uma tradução mental da forma como a realidade (da violência intrafamiliar) é percebida pelos participantes da pesquisa. O imaginário ocupa apenas uma parte do campo das representações a que estão presas diretamente as imagens iniciais da realidade (Laplantine \& Trindade, 1997). Em outras palavras, são as imagens de violência intrafamiliar que surgem na mente dos sujeitos antes que a cognição inicie seu processo de elaboração da idéia sobre a qual incidirá o conteúdo das conversas informais e as idéias do senso co-

\begin{tabular}{|c|c|c|c|c|c|}
\hline Categorias & $\begin{array}{c}\text { Sentimentos a respeito } \\
\text { da V.I. }\end{array}$ & Causas da V.I. & Conseqüîncias da V.I. & $\begin{array}{c}\text { Violência como } \\
\text { agressão física/abuso } \\
\text { sexual/negligência }\end{array}$ & Outras respostas \\
\hline \multirow{7}{*}{$\begin{array}{l}\text { Indicadores } \\
\text { (atributos) }\end{array}$} & Revolta & Revolta & Revolta & Revolta & Providências \\
\hline & Pena & Desemprego & Traumas & Maus tratos & Leis \\
\hline & Tristeza & Alcoolismo & Vingança & Espancamento & Buscar a Deus \\
\hline & Indignação & Ignorância & Roubo & Negligência & \multirow{4}{*}{$\begin{array}{l}\text { Os pais não } \\
\text { acompanham a vida } \\
\text { escolar dos filhos }\end{array}$} \\
\hline & Compaixão & Pobreza & Agressividade & Agressão verbal & \\
\hline & Angústia & $\begin{array}{l}\text { Baixa escolaridade dos } \\
\text { pais }\end{array}$ & Crianças frustradas & Humilhações & \\
\hline & Impotência & $\begin{array}{l}\text { Falta de estrutura } \\
\text { familiar }\end{array}$ & $\begin{array}{l}\text { Crianças com baixa } \\
\text { auto-estima }\end{array}$ & Brigas entre o casal & \\
\hline
\end{tabular}

Quadro 1. Representações de Violência Intrafamiliar (segundo o foco de significações atribuídas). 
mum.

Tal pressuposto talvez justifique a facilidade com que as respostas puderam ser categorizadas teoricamente, a partir do que Bardin (1977, p.82) chama de "palavras plenas", isto é, "palavras portadoras de sentido" - substantivos e adjetivos como: tristeza, compaixão, revolta, ignorância e outras -, correspondendo a uma categorização semântica (ver Quadro 1).

As categorias semânticas podem constituir também categorias simbólicas do tema, ou seja, a identificação do campo afetivo/emocional pelo qual o sujeito apreende, da realidade, a violência intrafamiliar contra crianças e adolescentes e que vai constituir sua percepção/representação.

No entendimento dessas categorias de sentido semântico/simbólico, chama a atenção a palavra "revolta", que semanticamente diz respeito à "justa indignação" (Sacconi, 1996 , p. 585), e que aparece em todas as categorias. Simbolicamente pode corresponder à parte do conhecimento que subsiste ao processo de construção das representações sociais e que, segundo Moscovici (2003), pode produzir o conhecimento verdadeiro. Assim, subsistindo uma "justa indignação" dos professores pesquisados quanto às causas, conseqüências e sentimentos provocados pela violência intrafamiliar contra crianças e adolescentes, resta verificar como a natureza convencional e prescritiva das representações sociais vai incidir sobre a "revolta" inicial e determinar e motivar, posteriormente, as atitudes desses sujeitos frente ao problema, o que será visto e discutido adiante.

A categorização anteriormente apresentada permite a análise do fenômeno em estudo no sentido das quatro dimensões do tema-objeto de que fala Bardin (1977): dimensão I - a origem do objeto/fenômeno, aqui denominada "causas"; dimensão II - as implicações do objeto, que se chamou de "conseqüências"; dimensão III - a descrição do fenômeno, denominada "tipos de violência"; dimensão IV - o sentimento face ao objeto ou "sentimentos".

Percebe-se que as dimensões citadas por Bardin (1977), se alteradas em uma de suas seqüências, transmitem a noção de processo: origem do fenômeno (causas da violência intrafamiliar), descrição do fenômeno (tipos de violência intrafamiliar), suas implicações (conseqüências na criança, nos sujeitos pesquisados e em terceiros), significando que os participantes da pesquisa possuem uma idéia clara da extensão do problema em termos de processo, já que o fenômeno violência intrafamiliar ocorre em uma sequiência lógica: causas do fenômeno, tipificação e conseqüências. A dimensão "sentimentos" funcionaria, neste caso, como o ponto que determina a reprodução do processo ou sua interrupção, através das atitudes diante do problema, conforme já dito.

Uma correspondência entre os maiores percentuais obtidos $(59,6 \%$ causas e 36,2\% sentimentos) leva à seguinte compreensão: mais da metade dos professores pesquisados percebe a violência intrafamiliar a partir de suas causas. Isto significa que a representação pode estar centrada sobretudo na reprodução da violência, considerando que a criança agredida de hoje pode se transformar em um futuro agressor, conforme o modelo psicopatológico apresentado por Gelles (citado por Guerra, 1993), no qual experiências de violência intrafamiliar na infância desencadeiam estados psicopáticos na idade adulta.

Em outra perspectiva, a maior preocupação com as causas da violência intrafamiliar denotaria, também, que a atenção dos participantes da pesquisa está voltada para a figura do agressor, isentando, de certa forma, a sociedade de responsabilidades em relação ao problema, conforme esclarece Guerra (1993). Por outro lado, a significação atribuída às causas da violência delega às vítimas - crianças e adolescentes - uma atenção secundária. Considerando que as respostas não são excludentes e que $36,2 \%$ dos participantes referiram-se a sentimentos para a atribuição de sentidos à violência intrafamiliar, pode-se deduzir que a representação social nesse grupo circula não em nível predominantemente cognitivo, mas sobretudo afetivo-emocional. Essa leitura faz sentido visto que a categoria "sentimentos" pode gerar conflitos, contradições e ambivalências com relação à violência intrafamiliar, face à negação do óbvio pela ideologia da autoridade paterna (reprodução do modelo).

A categoria "sentimentos" pode significar, ainda, para as representações sociais, segundo uma definição de Moscovici (1978), uma "encruzilhada" entre o sentimento do indivíduo (que pode induzí-lo à ação/ruptura) e a ideologia dos grupos sociais (que pode levá-lo à inação/reprodução). Nessa encruzilhada situam-se as representações sociais, entendendo-se, no caso deste trabalho, que a representação social segundo o foco das significações atribuídas vai depender do resultado do "embate" entre o sentimento pessoal (ação/inação) e a ideologia dos grupos (autoridade paterna/ materna). Teoricamente, corresponde à interface cognitiva entre ação individual e ideologia social (Stratton \& Hayes, 1994), a qual passa pelo senso comum, isto é, pela concepção fragmentada de mundo, conforme Luckesi (1994).

Quanto à categoria "consequiências" e seu percentual relativamente menor $(22,3 \%)$ depreende-se que os professores pesquisados - cuja maioria não possui em suas salas alunos em situação de violência intrafamiliar - não se encontram devidamente atentos para as implicações pessoais, sociais e pedagógicas do problema.

Szymanski (2001) afirma que, depois da família, a escola é o lugar de se decodificarem linguagens (marcas no corpo, comportamentos agressivos e outros) e que, além disso, como instituição, quer pública ou privada, a escola é responsável pela prática concreta de seus agentes, a qual implica uma rede de interações complexas entre professor e aluno, envolvendo várias dimensões, inclusive a da violência intrafamiliar.

Brino e Williams (2003) esclarecem que a escola é o lugar ideal para a detecção e a intervenção em casos de violência intrafamiliar contra a criança e adolescentes, lembrando que um dos objetivos da instituição escolar é a garantia de qualidade de vida aos alunos, ao mesmo tempo em que promove a sua cidadania.

E importante ressaltar que apenas um contingente pequeno da amostra significou/representou a violência intrafamiliar de acordo com as indicações referendadas pelo Ministério da Saúde e pela literatura científica sobre violência, citadas nesta pesquisa.

As respostas à questão - "Quais são, na sua opinião, os principais sinais ou sintomas de um aluno que sofre violência intrafamiliar?" - podem ser analisadas em conjunto, haja vista a possibilidade de um sintoma desencadear o outro. É o caso dos sinais físicos, por exemplo, que podem se refletir tanto na agressividade quanto no isolamento do aluno. Se as marcas físicas (21,3\% das respostas) denotam mais claramente a 
violência intrafamiliar, os comportamentos de agressividade contra professores e colegas $(73,4 \%)$, de isolamento, tristeza e choro $(90,4 \%)$, por exemplo, também chamaram a atenção dos professores pesquisados, significando que eles associam tais comportamentos à violência intrafamiliar.

Esse reconhecimento mostra-se incompatível com as respostas nas quais os sujeitos declararam obter informações sobre violência intrafamiliar por meio de conversas informais, mídia e pesquisas. Nesse entendimento, o aluno vítima da violência não constitui, por si só, uma fonte de informação, embora represente, na verdade, mais do que isso: os efeitos da consumação do próprio ato, no caso, o da violência intrafamiliar.

A respeito dos indicadores de violência intrafamiliar, assim se expressaram alguns participantes: P-55 identifica a violência pelas "marcas no corpo", mas afirma que "a lei protege muito os adolescentes". P-7 identifica sinais de violência pela "dispersão em sala, agressividade, retração e baixo rendimento escolar do aluno", porém se pergunta "até que ponto devemos defender a criança que só faz coisas erradas?"

Pelas respostas obtidas, a violência intrafamiliar parece justificar-se teoricamente por um tipo de dispositivo sociológico que construiu uma essência pacífica para o brasileiro e no qual a violência real é negada (Chauí, citada por Andrade, 2003).

Observa-se, então, uma "negação" das evidências (criança com hematomas, agressiva, isolada...) em função de determinações sociais - a autoridade paterna - demonstrando, conforme Moscovici (2003), a comprovação de que não se está consciente de algumas coisas óbvias pelo fato de elas não serem abordadas especificamente. Isso, por sua vez, leva à aceitação de idéias, comportamentos e atitudes sem uma discussão crítica a respeito de suas inúmeras implicações subjetivas e sociais.

No sentido filosófico, essa "negação" das evidências pode ser tratada como um conflito entre subjetivo e objetivo, no qual a autoridade paterna funciona como predicado aceito e a existência de violência intrafamiliar como predicado negado. A análise demonstra que o fenômeno não atingiu, pelo menos nos professores pesquisados, o nível de significação esperado que seria o da reflexão esclarecida ou da tomada de consciência em busca de soluções para essa problemática.

\section{Unidade de registro 3 (atitudes)}

As respostas desta unidade serão analisadas em conjunto, tendo em vista a proximidade observada entre elas quanto ao processo desencadeado pelo contato com alunos vitimizados pela violência intrafamiliar e a respectiva atitude diante do fato. Em outras palavras, seria como verificar a ação (da violência intrafamiliar) e a reação (dos sujeitos) frente ao problema.

Sobre contatos diretos ou indiretos dos participantes da pesquisa com alunos em situação de violência intrafamiliar, 48,04\% responderam não ter contato e 51,06\% responderam afirmativamente. Os casos citados foram: agressão física, por alcoolismo do pai; queimaduras, pelo pai; abuso sexual pelo padrasto; agressão física paterna à criança em sala de aula diante da recusa a fazer as tarefas escolares; pai viciado em drogas que batia na mãe e nas crianças; mãe apoiando filho mais velho em violência física e moral contra o irmão menor; menina espancada por mãe prostituta e obrigada a presenciar as cenas de sexo da mãe com parceiros; aluno com queimaduras de ponta de cigarro; criança dormindo amarrada para que os pais pudessem sair à noite; mãe alcoólatra espancando os filhos, dentre outros relatos.

Configura-se, nos casos relatados, violência tanto física quanto psicológica que pode levar a uma confusão nas imagens parentais, deixando os pais de representar o papel de protetor, passando ao de agressor (Ribeiro \& Borges, 2001). O mesmo ocorre quando a mãe (ou o pai) é conivente com maus tratos de irmãos maiores contra irmãos menores. Ela, mesmo não exercendo diretamente o papel de agressora, exerce o de testemunha, um dos papéis citados por Koller e De Antoni (2004), presentes nos atos de violência. A testemunha, tanto quanto o agressor, tem a sua cota de responsabilidade.

Às perguntas: "o que você faria se tivesse em sua sala de aula situações comprovadas de violência intrafamiliar?" e "o que faria diante de suspeitas dessa violência?" -, as respostas foram bastante semelhantes.

Nas duas respostas, a grande maioria dos participantes $(77,7 \%$ e $82,98 \%$, respectivamente) prefere agir no âmbito da sala de aula ou com encaminhamentos aos serviços de orientação psicopedagógica da própria instituição escolar. $\mathrm{O}$ percentual de sujeitos que denunciam ou encaminham crianças/adolescentes vitimizadas pela violência intrafamiliar aos órgãos e instituições específicos ainda é relativamente pequeno $(11,7 \%$ e $12,98 \%$, respectivamente), se comparado com o percentual dos que agem no âmbito da própria instituição, apesar de as respostas não serem excludentes.

Esse agir no âmbito da instituição pode estar relacionado, em parte, com o fato de os sujeitos demonstrarem desconhecer o ECA $(9,6 \%)$ e os órgãos/instituições de proteção ao menor $(25,53 \%)$. Mas pode também, sobretudo, estar associado ao fato de que $73,4 \%$ dos professores pesquisados não concordam ou concordam apenas parcialmente com o referido estatuto, acreditando que suas normas necessitam ser revistas.

Por outro lado, os referidos percentuais referendam o discurso de participantes da pesquisa $(41,5 \%)$ que justificam subliminarmente a violência, como por exemplo: “(...) não concordo (com o ECA) na questão do aluno ser intocável" ( P- 21), ou, ainda, na significação atribuída à violência: "(...) devemos educar nossos filhos da nossa maneira, bater faz parte (sem agressão)" (P- 25).

Algumas leituras podem ser feitas a partir desses dados:

1. A escola arroga para si o direito de resolver "a seu modo" esses problemas apesar de, segundo Brino e Williams (2003), ela constituir o espaço ideal para detecção e intervenção nesse tipo de violência. No caso das escolas dos professores pesquisados, essas parecem não contar com profissionais suficientemente preparados para tomar esse tipo de atitude.

2. O problema da violência intrafamiliar é ainda visto como algo afeito sobretudo à esfera privada, não havendo ainda uma passagem nitidamente explícita para o domínio do espaço público, no caso, a instituição escolar. Encaminhar crianças/adolescentes vitimizados pela violência intrafamiliar a um serviço de atendimento dentro da própria instituição significa tratar o problema em sua dimensão privada, "entre quatro paredes", o que não constitui uma 
atitude recomendada pelo ECA e por especialistas da área.

3. Finalmente, pode-se supor que as atitudes de boa parte dos professores pesquisados apontam para uma não implicação pessoal nos casos de identificação e encaminhamento de casos de violência intrafamiliar. Parece haver, então, uma certa ruptura ou descontinuidade entre os sentimentos expressos e as ações e atitudes efetivamente tomadas pelos sujeitos, o que evidencia os conflitos, as contradições e as ambivalências vividas pelos sujeitos com relação à violência intrafamiliar, percebida no contexto escolar.

\section{Conclusão}

Por meio deste estudo foi possível apreender as representações sociais em suas dimensões "informação", "campo das representações" e "atitudes" e parece plausível afirmar que as representações sociais aqui inferidas compõem o quadro de referência das ações/atitudes dos professores pesquisados. Da mesma forma, desempenham um papel importante na condução do fazer educativo desses sujeitos e, por extensão social, de professores do ensino fundamental no que tange a sua relação com alunos vitimizados pela violência intrafamiliar.

Com relação à dimensão informação, percebeu-se que o grupo pesquisado demonstrou dar um tratamento informal ao tema violência intrafamiliar, tanto na obtenção da informação quanto na discussão do assunto com seus pares.

Também se observou que a maioria dos sujeitos que afirma conhecer o ECA diz não concordar com essa Lei, o que leva à consideração de que suas opiniões acerca do Estatuto estariam indo ao encontro da manutenção de um modelo de autoridade no qual os pais têm total poder sobre seus filhos, a despeito de qualquer ação exterior ao contexto familiar.

Quanto à dimensão campo das representações, ressaltase que os professores atribuem significações à violência intrafamiliar principalmente a partir das causas e sentimentos gerados por esse fenômeno. Pode-se concluir que os sentimentos funcionariam, nesse caso, como ponto de partida a determinar uma excessiva preocupação com a reprodução da violência, uma reprodução de modelos interpretativos da realidade, a exemplo do modelo da autoridade paterna, como também a necessidade de se eleger culpados, centrando suas reflexões na figura do agressor. Dessa forma, o professor e a instituição escolar estariam se isentando de participação e implicação na solução do problema.

Quanto às atitudes, foi observado que diante de casos confirmados e/ou de suspeita de violência intrafamiliar tanto os professores de escola pública quanto os de escola privada agiriam, em sua maioria, no âmbito da própria escola o que, de certa forma, contraria o ECA, mesmo tendo a maioria dito conhecer as suas orientações.

Reforça-se a importância dos resultados obtidos em relação à fonte de informação dos participantes, que se revelou transitar, na sua maioria, por meio de conversas informais. $\mathrm{E}$ ainda, de acordo com Brino e Williams (2003), confirma-se o descompasso entre o que prevê o ECA - que os sujeitos dizem conhecer - e o que fariam efetivamente os professores, ao depararem-se com casos de violência intrafamiliar.

Os resultados obtidos neste trabalho, diante dos objetivos propostos, levam à conclusão de que a representação social da violência intrafamiliar contra crianças e adoles- centes, para grande parte dos participantes pesquisados, ainda passa pela consideração do poder da autoridade que dá direito aos pais de educar os filhos como melhor lhes convier. Isso porque, apesar de haver por parte dos professores preocupação quanto às causas, consequiências e tipos de violência praticados, nenhuma delas parece ser suficientemente forte para induzir a maioria dos sujeitos a ações específicas fora do âmbito da escola. Da mesma forma, os sentimentos expressos sobre a violência intrafamilar, que compareceram na fala de uma boa parte dos participantes, não os move em direção a ações e busca de solução situadas fora do contexto da escola.

Observa-se, então, uma relação contraditória entre preocupação, sentimentos e ação efetiva, o que expressa a possibilidade de um conflito vivenciado pelos professores pesquisados, o qual pode estar relacionado com os aspectos paradoxais que envolvem a violência intrafamiliar. É o caso, por exemplo, de uma maior divulgação do problema pela mídia, na atualidade (chamando a atenção da sociedade), em contraste com a força do discurso social, em sua informalidade, permeado de saberes do senso comum, determinando o poder da família sobre os filhos. É como se houvesse uma contrapartida: enquanto a mídia tenta ampliar a visão do problema para além dos muros da residência familiar, a tradicional idéia de autoridade paterna parece envolver o assunto com o invólucro do silêncio, impedindo que ele seja tratado fora do espaço familiar. As políticas de governo criaram o ECA e os órgãos de atendimento e assistência à infância e à adolescência, mas os grupos sociais resistem, preferindo defender uma "natureza" brasileira pacífica, sujeita a eventuais crises de violência. A mídia tenta demonstrar a gravidade do problema, enquanto os grupos sociais permanecem com seu discurso de globalizações, de reduções semânticas e de ocultação/negação da realidade.

Diante das considerações firmadas anteriormente, reforça-se a premissa de que falta uma discussão qualificada acerca da violência intrafamiliar, no âmbito da formação inicial e continuada dos professores, o que os tem levado, muitas vezes, à escolha de caminhos equivocados em relação ao encaminhamento e à solução dados ao problema (Brino \& Williams, 2003). Seguindo esse raciocínio, este trabalho chama à reflexão todas as esferas da sociedade, principalmente a escolar, e todos os atores envolvidos no processo de educar para a cidadania.

\section{Referências}

Andrade, A. P. de (2003). Violência doméstica contra crianças e adolescentes: prevenção, repressão e proteção à vítima no âmbito brasileiro e latino-americano. Revista de Informação Legislativa, 160, 147-162.

Ariès, P. (1981). História social da criança e da família. (D. Flaksman, Trad.). Rio de Janeiro: RTC, original publicado em 1973.

Bardin, L. (1977). Análise de conteúdo. (L. A. Reto \& A. Pinheiro, Trad.). Lisboa: Edições 70-Persona.

Bonfim, Z. A. C. \& Almeida, S. F. C. de (1992). Representação social: conceituação, dimensão e funções. Revista de Psicologia, 9(1-2), 75- 89.

Brasil (1988). Constituição da República Federativa do Brasil. Brasília: Senado Federal. 
Brasil (1990). Lei 8.069/90, de 13 de Julho de 1990. Brasília: Senado Federal.

Brino, R. de F. (2002). Capacitação do educador acerca do abuso sexual infantil Dissertação de Mestrado, Universidade Federal de São Carlos, São Carlos.

Brino, R. de F. \& Williams, L. C. de A. (2003). Concepções da professora acerca do abuso sexual infantil. Cadernos de Pesquisa, 119, 113-128.

Bronfenbrenner, U. (1996). A ecologia do desenvolvimento humano: experimentos naturais e planejados. (M. A. V. Veronese, Trad) Porto Alegre: Artmed, original publicado em 1994.

Carvalho, D. B. B. de \& Rodrigues, A. A. (1998). A violência doméstica contra crianças e adolescentes: análise do fenômeno no Distrito Federal. Ser Social, 2, 57-84.

Freitas, S. N. \& Castro, S. F. (2004). Representação social e educação especial: a representação dos professores de alunos com necessidades educativas especiais incluídos na classe comum do ensino regular. Retirado em 29/05/2004 em: http:// educacaoonline.pro.br

Guerra, V. N. de A. (1993). Violência física doméstica contra crianças e adolescentes: os difíceis caminhos do conhecimento científico. Temas em Psicologia, 3, 127-135.

Guerra, V. N. de A. (2001). Violência de pais contra filhos: a tragédia revisitada. São Paulo: Cortez.

Guerra, V. N. de A. \& Azevedo, M. A. (2000). Infância e violência doméstica. São Paulo: Cortez.

Jodelet, D. (1993). Représentations sociales: un domaine en expansion. Em D. Jodelet (Org.), Les représentations sociales. (pp. 31-61). Paris: PUF.

Koller, S. H. \& Amazarray, M. R. (1998). Alguns aspectos observados no desenvolvimento de crianças vítimas de abuso sexual. Psicologia Reflexão e Crítica, 1(3), 559-578.

Koller, S. H. \& De Antoni, C. (2004). A pesquisa ecológica sobre violência no microssistema familiar. Em S. Koller (Org.), Ecologia do desenvolvimento humano (pp. 311-336). São Paulo: Casa do Psicólogo.

Koller, S. H. \& Lisboa, C. (2004). O microssistema escolar e os processos proximais: exemplos de investigações científicas e intervenções práticas. Em S. Koller (Org.), Ecologia do desenvolvimento humano (pp. 337-354). São Paulo: Casa do Psicólogo.
Laplantine, F. \& Trindade, L. (1997). O que é imaginário. São Paulo: Brasiliense.

Luckesi, C. C. (1994). Filosofia da educação. São Paulo: Cortez.

Moscovici, S. (1978). A representação social da psicanálise. Rio de Janeiro: Zahar.

Moscovici, S. (2003). Representações sociais: investigações em psicologia social. Petrópolis: Vozes.

Oliveira, F. O. de \& Werba, G. C. (2003). Representações Sociais. Em M. N. Strey (Org.) Psicologia social contemporânea: livro-texto. (pp. 104-117). Petrópolis: Vozes.

Ravazzola, M. C.(1997). La violência y los vínculos: diálogo entre A. Loketek y M. C. Ravazzola (pp. 91-106). Sistemas Familiares, Año 13, n. 3,91-106.

Ribeiro, M. A. \& Borges, L. M. (2001).Violência sexual na família: um estudo de caso [Resumo]. Em Anais do XVIII Congresso Interamericano de Psicologia (CD Rom) Santiago, Chile: Sociedade Interamericana de Psicologia.

Rosa, E. M. (2004). Radiografia de um processo social: um estudo sobre o discurso jurídico a respeito da violência contra crianças. São Paulo: Casa do Psicólogo.

Sacconi, L. A. (1996). Minidicionário Sacconi. São Paulo: Atual.

Santos, M. de F. S. (1994). Representação social e a relação indivíduo sociedade. Temas em Psicologia, 3, 133-142.

Stratton, P. \& Hayes, N. (1994). Dicionário de psicologia.(E.Rovais, Trad.) São Paulo: Pioneira. original publicado em 1993.

Szymanski, H. (2001). A relação famílialescola: desafios e perspectivas. Brasília: Plano.

Recebido em 09.11.2005

Primeira decisão editorial em 25.01.2006

Versão final em 11.05.2006

Aceito em 02.06.2006 